\title{
Sosialisasi Pencegahan Perilaku Phubbing Pada Generasi Millenial
}

\author{
${ }^{1}$ Reski P, ${ }^{2}$ Yuli Apriati, ${ }^{3}$ Sigit Ruswinarsih \\ ${ }^{1,2,3}$ Pendidikan Sosiologi, Universitas Lambung Mangkurat \\ Email: ${ }^{1}$ reski@ulm.ac.id, ${ }^{2}$ Yuliapriati@ulm.ac.id, ${ }^{3}$ Sigitruswinarsih@ulm.ac.id
}

\begin{abstract}
This community service aims to provide an understanding to the millennial generation regarding phubbing behavior and also provide ways to prevent this behavior through socialization activities to prevent phubbing behavior in the millennial generation of Sungai Miai sub-district, Banjarmasin City. This service activity is carried out with two methods, namely: 1. Lecture Method, used to explain the material that has been prepared by the service team regarding Phubbing Behavior, the impact and efforts to prevent this behavior. The Question and Answer method is used to respond to the extent of the participants' understanding of the material that has been prepared by the service team regarding phubbing behavior and its prevention efforts. The implementation of community service was successfully carried out by the service team with enthusiasm from the service participants and also from the questionnaire filled out by the participants with the majority being very satisfied with the service activities carried out by the service team. It is hoped that this socialization regarding the prevention of phubbing behavior will continue with a wider target audience considering the negative impact of this smartphone, namely phubbing behavior is very concerning, especially what happens in the millennial generation and it is hoped that through this socialization the millennial generation will be wiser in using smartphones in everyday life.
\end{abstract}

Keywords : Socialization, Phubbing, Millennial Generation

\begin{abstract}
Abstrak
Pengabdian pada masyarakat ini bertujuan memberikan pemahaman kepada generasi millenial mengenai perilaku phubbing dan juga memberikan cara pencegahan perilaku tersebut melalui kegiatan Sosialisasi pencegahan perilaku phubbing pada generasi millenial kelurahan Sungai Miai, Kota Banjarmasin. Kegiatan pengabdian ini dilakukan dengan dua metode yaitu: 1 . Metode Ceramah, digunakan untuk memaparkan materi yang telah disusun oleh tim pengabdian mengenai Perilaku Phubbing, dampak dan upaya pencegahan perilaku tersebut. Metode Tanya Jawab, digunakan untuk merespon sejauh mana tingkat pemahaman peserta seputar materi yang telah disusun oleh tim pengabdian mengenai perilaku phubbing dan upaya pencegahannya. Pelaksanaan pengabdian kepada masyarakat ini berhasil dilakukan oleh tim pengabdian dengan antusias peserta pengabdian dan juga dari angket yang diisi oleh peserta dengan mayoritas merasa sangat puas dengan kegiatan pengabdian yang telah dilakukan oleh tim pengabdian. Diharapkan sosialisasi mengenai pencegahan perilaku phubbing ini tetap berlanjut dengan sasaran mitra yang lebih luas lagi mengingat dari dampak negatif dari smartphone ini yaitu perilaku phubbing sangat memprihatinkan apalagi yang terjadi di generasi millenial dan
\end{abstract}


diharapkan melalui sosialisasi ini generasi millenial semakin bijak menggunakan smartphone dalam kehidupan sehari-hari.

\section{Kata Kunci: $\quad$ Sosialisasi, Phubbing, Generasi Millenial}

\section{Pendahuluan}

Kemajuan peradaban seakan menuntut penyelarasan dengan berbagai sektor kehidupan manusia. Kehadiran teknologi menjadi salah satu penanda dari kemajuan itu. Tidak terkecuali teknologi komunikasi yang kian memperlihatkan geliatnya. Beragam perangkat komunikasi bermunculan hingga lahirnya smartphone yang menjadi angin segar bagi kemudahan komunikasi yang ditawarkan melalui fitur-fiturnya.

Generasi millenial pun tidak terlepas dari pesona smartphone tersebut. Di Indonesia, pemanfaatan telepon seluler (smartphone) dapat dilihat dari hasil Susenas 2017 menunjukkan bahwa memang generasi millenial lebih unggul jika dibandingkan dengan generasi-generasi sebelumnya. Pada Gambar 1 terlihat bahwa persentase generasi millenial di Indonesia yang menggunakan telepon seluler (HP)/ Nirkabel pada tahun 2017 sudah mencapai 91,62 persen. Persentase ini jauh lebih tinggi jika dibandingkan dengan Generasi X yang sebesar 77,02 persen dan Generasi baby boom dan veteran yang hanya sebesar 43,72 persen (KPPPA, 2018:4).

Ada sebanyak 98,2 persen millennial menggunakan smartphone sebagai device utama ketika mengakses internet. Hal ini menunjukkan bahwa telepon seluler pintar (smartphone) merupakan gawai yang mereka bawa kemana-mana, dari mulai bangun tidur hingga tidur mereka membawa smartphone. Apalagi mayoritas mereka merupakan heavy user dan addicted user (IDN Media, 2019: $58)$.

Berdasarkan beberapa pendapat para ahli dari berbagai negara dan profesi, penentuan siapa generasi millenial dapat ditarik kesimpulan bahwa generasi millenial adalah mereka yang dilahirkan antara tahun 1980 sampai dengan 2000. Selanjutnya konsep generasi millenial Indonesia adalah Penduduk Indonesia yang lahir antara tahun 1980-2000 (KPPPA, 2018: 16).

Beranjak dari popularitas smartphone yang tidak bisa dipisahkan dari kehidupan manusia dan menjadi kian digandrungi oleh generasi millenial, sebenarnya tidak ada yang salah dari kehadiran smartphone tersebut karena setiap produk yang diciptakan itu mempunyai tujuan yang baik, hanya terkadang di dalam penggunaannya ada oknum yang menyalahgunakan ataupun sekedar berlebihan dalam penggunaannya. Disinilah kemudian titik tolak sebagai penggunaan smartphone yang tidak semestinya sehingga melahirkan gejala ataupun perilaku -perilaku sebagai akibat keberadaannya.

Salah satu perilaku tersebut yaitu Phubbing. Phubbing merupakan kependekan dari Phone Snubbing. Phone Phubbing adalah kebosanan seseorang dalam berbincang secara langsung dengan lawan bicara atau dengan orang lain dan beralih berbincang dengan orang lain melalui smartphone (Juwita, 2019: 127). Hasil penelitian yang dilakukan Varoth Chotpitayasunondh \& Karen M. Douglas (2018) dengan judul The effects of "phubbing" on social interaction. Hasil penelitian tersebut menunjukkan bahwa peningkatan phubbing secara signifikan dan negatif mempengaruhi persepsi kualitas komunikasi dan kepuasan hubungan. 
Berdasarkan hasil penelitian selanjutnya yang menjadi dasar dilaksanakannya pengabdian kepada masyarakat ini dilakukan oleh salah satu anggota tim pengabdian yaitu Reski (2020) dengan judul penelitian Daya Tarik Interaksi Dunia Maya (Studi perilaku Phubbing pada Generasi Millenial di Kota Banjarmasin) ditemukan bahwa para generasi millenial tidak serta merta melakukan phubbing begitu saja sebab mereka juga menyadari bahwa perilaku phubbing tergolong perilaku yang tidak baik tetapi mereka tetap melakukannya. Penyebab para generasi millenial melakukannya yaitu mengalihkan perasaan bosan, menghindari topik pembicaraan yang tidak disukai, dan teman disekitar juga melakukan phubbing.

Dari hasil penelitian tersebut memperlihatkan bahwa generasi millenial menyadari saat diri mereka melakukan phubbing itu termasuk perilaku yang tidak baik, tetapi mereka tetap melakukannya karena berbagai alasan salah satunya bahwa orang disekitarnya juga melakukan phubbing terungkap bahwa ada stimulus berupa perilaku phubbing yang diterima sehingga mereka juga memberikan respon atas perilaku yang diterima tersebut dengan melakukan hal yang sama yaitu phubbing. Sehingga disini perlu dilakukan sosialisasi pencegahan phubbing bagi generasi millenial agar mereka bisa menghindari perilaku tersebut.

\section{Metode Pengabdian}

Untuk melaksanakan kegiatan pengabdian masyarakat ini tim mensosialisasikan pencegahan perilaku phubbing pada generasi millenial sehingga perilaku phubbing bisa dihindari. Dalam pelaksanaan kegiatan ini digunakan beberapa metode, antara lain:

1. Metode ceramah, yaitu digunakan untuk memaparkan materi yang telah disusun oleh tim pengabdian mengenai sosialisasi pencegahan perilaku phubbing.

2. Metode Tanya Jawab, yaitu digunakan untuk merespon sejauh mana tingkat pemahaman peserta sosialisasi pencegahan perilaku phubbing atas apa yang telah disampaikan oleh Tim Pengabdian.

Tahapan kegiatan yang dilakukan adalah :

1). Melakukan koordinasi dengan pihak terkait

2). Menentukan waktu pelaksanaan

3). Melaksanakan pengabdian

\section{Hasil dan Pembahasan}

Program pengabdian kepada masyarakat dengan judul "Sosialisasi pencegahan perilaku phubbing pada generasi millenial kelurahan Sungai Miai, Kota Banjarmasin" telah dilaksanakan pada hari Sabtu, 19 Juni 2021 secara virtual melalui platform zoom. Peserta sosialisasi adalah para generasi millenial. Program pengabdian ini dilaksanakan dengan metode ceramah dan tanya jawab. Kegiatan ini diawali dengan penyampaian substansi inti mengenai Perilaku phubbing dan cara mencegahnya secara jelas, tegas serta interaktif dengan peserta kegiatan sosialisasi, sambil sesekali mempertanyakan mengenai pemahaman awal peserta mengenai perilaku Phubbing.

Tim Pengabdian menjelaskan mengenai Phubbing merupakan kependekan dari Phone Snubbing. Phone Phubbing adalah kebosanan seseorang dalam berbincang secara langsung dengan lawan bicara atau dengan orang lain dan beralih berbincang dengan orang lain melalui smartphone (Juwita, 2019: 127). 
Menjelaskan pengertian phubbing itu sendiri untuk lebih memahamkan peserta mengenai definisi konseptual dari Phubbing itu sendiri.
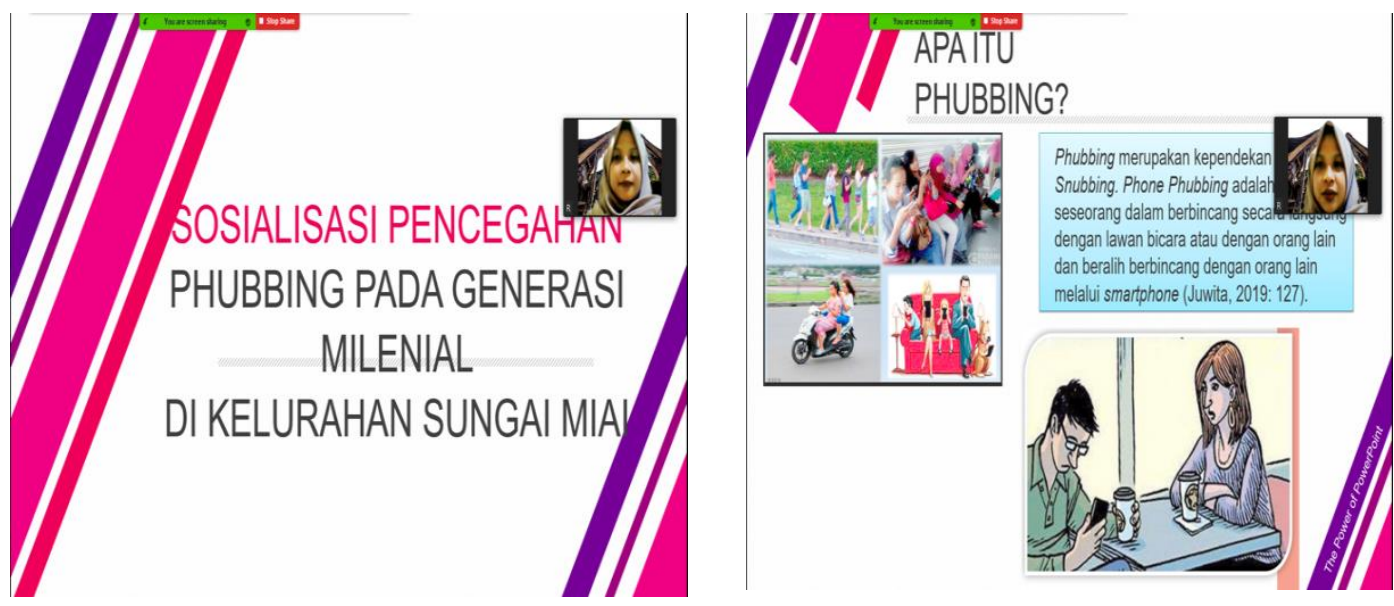

\section{Gambar 5.1. Penyampaian materi sosialisasi}

Hal selanjutnya yang pemateri sampaikan mengenai fakta Phubbing, hal tersebut dimaksudkan agar peserta sosialisasi mengetahui sejauh mana perilaku ini sudah merasuk dalam kehidupan para generasi millenial ditunjang dengan beberapa rujukan yang mendasari pentingnya sosialisasi ini yaitu Persentase generasi millenial di Indonesia yang menggunakan telepon seluler (HP)/ Nirkabel pada tahun 2017 sudah mencapai 91,62 persen. Persentase ini jauh lebih tinggi jika dibandingkan dengan Generasi X yang sebesar 77,02 persen dan Generasi baby boom dan veteran yang hanya sebesar 43,72 persen (KPPPA, 2018:4).

Studi Dr James Robert dkk Dari 143 responden, 70\% tidak bisa lepas dari ponsel dan melakukan phubbing $46 \%$ menjadi korban phubbing dari pasangannya sendiri Hasil penelitian yang dilakukan Varoth Chotpitayasunondh \& Karen M. Douglas (2018) dengan judul The effects of "phubbing" on social interaction. Hasil penelitian tersebut menunjukkan bahwa peningkatan phubbing secara signifikan dan negatif mempengaruhi persepsi kualitas komunikasi dan kepuasan hubungan.

Berdasarkan hasil penelitian selanjutnya yang menjadi dasar dilaksanakannya pengabdian kepada masyarakat ini dilakukan oleh salah satu anggota tim pengabdian yaitu Reski (2020) dengan judul penelitian Daya Tarik Interaksi Dunia Maya (Studi perilaku Phubbing pada Generasi Millenial di Kota Banjarmasin) ditemukan bahwa para generasi millenial tidak serta merta melakukan phubbing begitu saja sebab mereka juga menyadari bahwa perilaku phubbing tergolong perilaku yang tidak baik tetapi mereka tetap melakukannya. Penyebab para generasi millenial melakukannya yaitu mengalihkan perasaan bosan, menghindari topik pembicaraan yang tidak disukai, dan teman disekitar juga melakukan phubbing.

Setelah penyampaian materi selanjutnya tim pengabdian melakukan tanya jawab dengan para peserta sosialisasi. Terlihat keantusiasan peserta dalam mengungkapkan argumen dalam tanya jawab yang dilakukan terutama dengan penuturan mereka yang merasa bahwa memang perilaku seperti ini sangat dekat dengan mereka sehingga memang dirasa perlu untuk melakukan upaya 
pencegahan. Tahap akhir di tutup dengan foto bersama dengan para peserta pengabdian sekaligus menyudahi sosialisasi yang dilakukan oleh tim pengabdian.

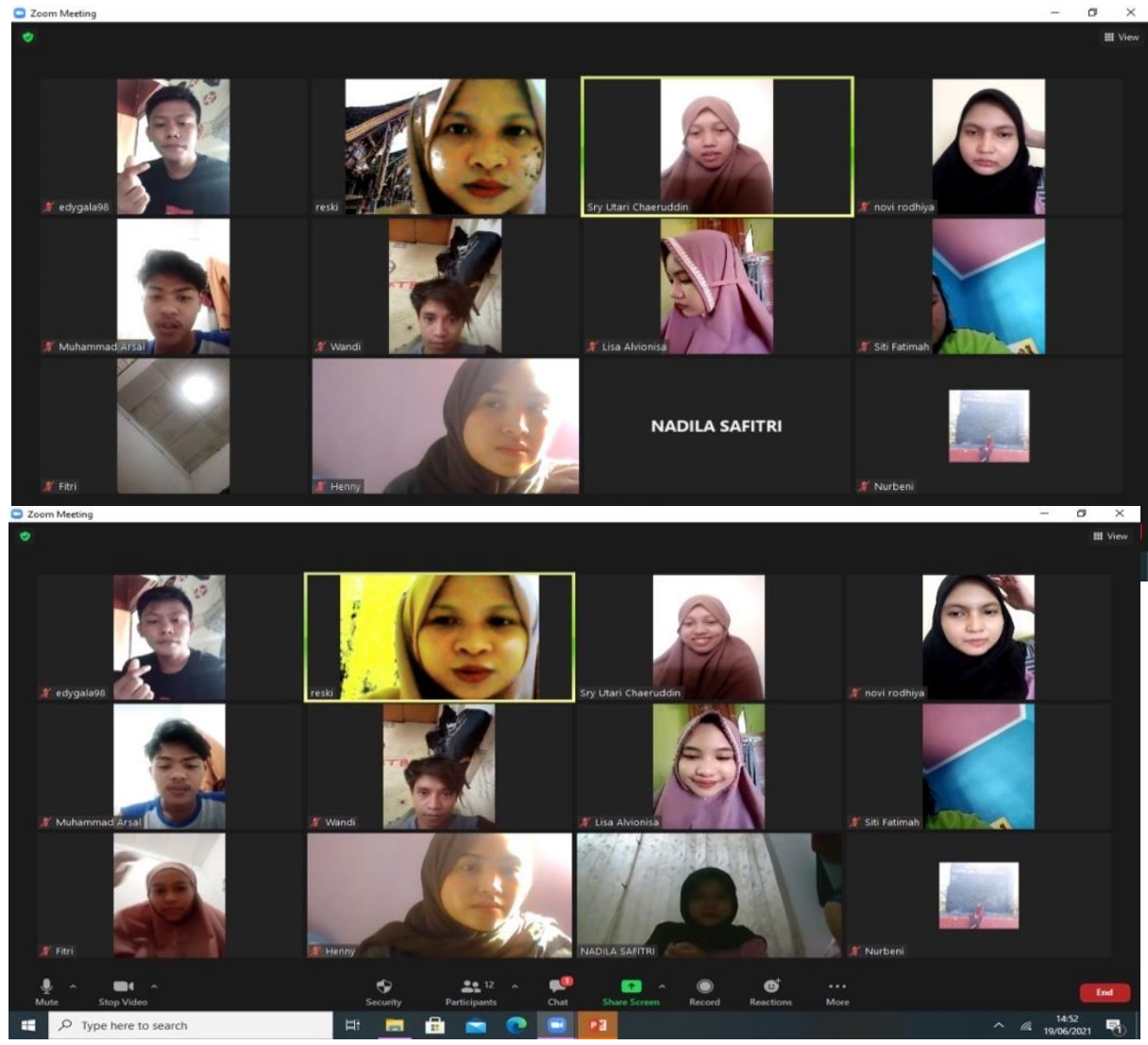

Gambar 5.3. Sesi Foto bersama dengan perserta sosialisasi

Setelah dilaksanakan kegiatan pengabdian masyarakat dalam bentuk Sosialisasi pencegahan perilaku phubbing yang diikuti oleh para generasi millenial di kelurahan Sungai Miai dapat dikemukakan bahwa sasaran kegiatan telah tercapai dengan baik. Terselenggaranya kegiatan sosialisasi serta antusias peserta yaitu generasi millenial dalam menyimak, bertanya, dan mendiskusikan pengalaman yang mereka hadapi terkait dengan perilaku phubbing ini baik dari segi dirinya sebagai pelaku Phubbing maupun sebagai Phubber.

Penyajian dan pemilihan materi sosialisasi sangat sesuai dengan kebutuhan para peserta dalam hal ini generasi millenial. Hal tersebut dilihat dari hasil angket yang dibagikan oleh Tim Pengabdian kepada para peserta sosialisasi. Adapun ditampilan dalam bentuk diagram di bawah ini: 


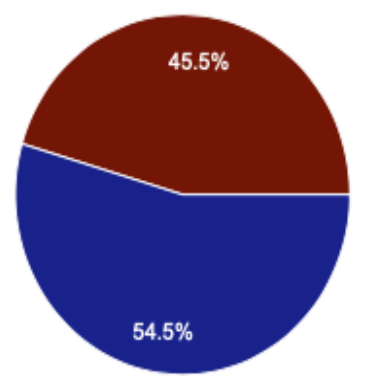

Sangat setuju

Setuju

Tidak Setuju

Sangat Tidak Setuju

Grafik 5.1. Materi PkM sesuai dengan kebutuhan peserta

Berdasarkan diagram diatas terlihat Bahwa materi Pengabdian yang dibawakan oleh tim pengabdian sesuai dengan kebutuhan para peserta kegiatan sosialisasi dengan persentase $54,5 \%$ mereka sangat setuju dengan kesesuaian materi dengan kebutuhan dan sisanya sebanyak 45,5\% merasa setuju. Berikut juga disajikan diagram kepuasan peserta mengenai kegiatan pengabdian yang telah dilakukan

Secara umum mitra puas dengan kegiatan pengabdian

11 responses

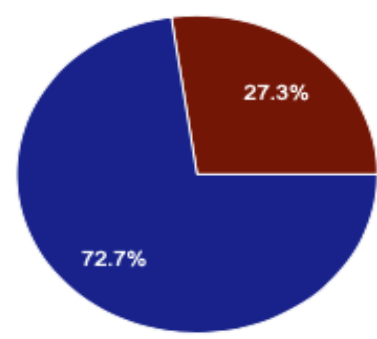

$$
\begin{aligned}
& \text { Sangat setuju } \\
& \text { Setuju } \\
& \text { Tidak Setuju } \\
& \text { Sangat Tidak Setuju }
\end{aligned}
$$

Grafik 5.2. Kepuasan mitra terhadap kegiatan pengabdian

Berdasarkan diagram yang di atas bahwa para peserta pengabdian merasa puas dengan persentase sebanyak $72,7 \%$ sangat setuju dan $27,3 \%$ merasa setuju. Hal tersebut semakin menegaskan bahwa kegiatan pengabdian yang telah dilakukan oleh Tim Pengabdian berhasil.

\section{Simpulan}

Program Pengabdian Masyarakat dengan judul "Sosialisasi pencegahan perilaku phubbing pada generasi millenial kelurahan Sungai Miai, Kota Banjarmasin" ini berjalan dengan baik, lancar dan menarik. Materi yang disampaikan dalam program sosialisasi ini mendapat perhatian dan respon positif dari para peserta pengabdian, hal ini dikarenakan materi yang disampaikan berkenaan dengan kehidupan sehari hari mereka berupa perilaku penggunaan smartphone yang mengarahkan pada perilaku phubbing serta cara mencegah perilaku tersebut yang mereka sadari tidak baik dan juga diskusi interaktif yang terjalin dengan pemateri pengabdian dan peserta pengabdian. 


\section{Saran}

Berdasarkan pada kesimpulan yang telah diuraikan diatas kami sebagai pelaksana program pengabdian masyarakat memberikan saran terkait bagaimana upaya pencegahan perilaku phubbing bagi generasi millenial. Adapun saran yang dapat kami berikan yaitu

1. Diharapkan sosialisasi mengenai pencegahan perilaku phubbing ini tetap berlanjut dengan sasaran mitra yang lebih luas lagi mengingat dari dampak negatif dari smartphone ini yaitu perilaku phubbing sangat memprihatinkan apalagi yang terjadi di generasi millenial.

2. Diharapkan Sosialisasi diberikan tidak hanya terbatas pada perilaku phubbing sebab masih banyak lagi dampak-dampak negatif dari penggunaan smartphone yang bisa mempengaruhi penggunanya, hal tersebut dimaksudkan agar masyarakat semakin bijak menggunakan smartphone dalam kehidupan sehari-hari.

\section{Daftar Pustaka}

IDN Media. (2019). Indonesia Millenial report 2019. Jakarta: IDN Research Institute.

Juwita, Lilis, et.al. (2019). Stop Phubbing. Jakarta: Rumah Media.

Kementerian Pemberdayaan Perempuan dan Perlindungan Anak dan BPS. 2018.

Profil Generasi Millenial Indonesia. Jakarta: Kementerian Pemberdayaan Perempuan dan Perlindungan Anak.

P, Reski, (2020). Daya Tarik Interaksi Dunia Maya (Studi perilaku Phubbing Generasi Millenial). Jurnal Pendidikan Equilibrium.

Varoth, Chotpitayasunondh dan Karen M. (2018). The effects of "phubbing" on social interaction. Journal of Applied Social Psychology Douglas University of Kent, United Kingdom. Diterbitkan. 
